\title{
Bur open Chronic lower respiratory diseases among demolition and cement workers: a population-based register study
}

\author{
Ellen Fischer Mølgaard, ${ }^{1}$ Harald Hannerz, ${ }^{2}$ Finn Tüchsen, ${ }^{3}$ Charlotte Brauer, ${ }^{1}$ \\ Lilli Kirkeskov ${ }^{1}$
}

To cite: Mølgaard EF, Hannerz $\mathrm{H}$, Tüchsen $\mathrm{F}$, et al. Chronic lower respiratory diseases among demolition and cement workers: a population-based register study. BMJ Open 2013;3: e001938. doi:10.1136/ bmjopen-2012-001938

- Prepublication history for online. To view these files please visit the journal online (http://dx.doi.org/10.1136/ bmjopen-2012-001938)

Received 7 August 2012 Revised 4 November 2012 Accepted 13 December 2012

This final article is available for use under the terms of the Creative Commons Attribution Non-Commercial 2.0 Licence; see http://bmjopen.bmj.com this paper are available

\section{ABSTRACT}

Objective: To estimate standardised hospitalisation ratios (SHR) for chronic lower respiratory diseases among demolition and cement workers in Denmark, 1995-2009.

Design: This is a population-based register study on data from 'the Occupational Hospitalisation Register'. SHR of chronic obstructive pulmonary disease (COPD) was calculated for both demolition and cement workers.

Settings: Register study with data from all hospitals in Denmark.

Participants: 895 demolition workers and 5633 cement and concrete workers were included in the study and all economical active men were used as reference group.

Results: We found a statistically significant high SHR for the cement workers, SHR=134 (95\% Cl 117 to 153$)$. The SHR for demolition workers was $131(95 \% \mathrm{Cl} 87$ to 188).

Conclusions: We find a higher risk of being hospitalised due to COPD in cement and concrete workers (significant) and demolition workers (insignificant) compared to gainfully employed men.

\section{INTRODUCTION}

Exposure to both organic and inorganic dust at work has become a focus of increasing concern during the past decade, especially the role of dust as a risk factor in the development of chronic obstructive pulmonary disease (COPD). ${ }^{1}$

The incidence of COPD in general is ${ }^{1}$ Department of Occupational and Environmental Medicine, Bispebjerg Hospital, Copenhagen, Denmark ${ }^{2}$ National Research Institute for the Working Environment, Copenhagen, Denmark ${ }^{3}$ Finn Tüchsen, Nordvej 16 a, DK-4000 Roskilde, Denmark

Correspondence to Dr Ellen Fischer Mølgaard; ellen.moel@gmail.com increasing. In 2004, COPD was the fourth most frequent cause of death in the world. In the general population in Denmark, the prevalence of COPD is found to be $9-12 \%$. $^{2}$

Tobacco smoke is the most well-known cause of COPD; however, work-related exposures are also thought to influence a decrease in lung function. ${ }^{3}$ In a recent report from the Danish Working Environment Research Fund they showed that dose-response correlations

\section{ARTICLE SUMMARY}

\section{Article focus}

- Do Danish workers in two dusty trades (the demolition, and the cement and concrete industry) have a higher risk of being hospitalised due to chronic lower respiratory diseases than the entire male labour force?

Key message

- We find a higher risk of being hospitalised owing to chronic lower respiratory diseases in cement and concrete workers (significant) and demolition workers (insignificant) compared to gainfully employed men.

Strengths and limitations of this study

- Strength that we both include inpatients and outpatients because of the nature of COPD.

- Strength that the OHR covers the entire gainfully employed population of Denmark.

- One limitation is the absence of individual smoking records.

- Another limitation is the chance of misclassification since we only have main job title and the rather unspecific diagnose-codes.

between dust exposure at work and COPD were found in several longitudinal studies. ${ }^{1}$

The Swedish Construction Industry Organisation for Working Environment Safety and Health has established a semiquantitative Job Exposure Matrix for building and construction industry; it shows an excessive exposure to dust in demolition work and concrete/ cement handling. ${ }^{4}{ }^{5}$ In the Netherlands ${ }^{6}$ and Norway, ${ }^{7}$ they investigated dust exposure and the development of COPD, and found that cement and concrete workers, along with miners and tunnel workers, were especially exposed. Vestbo $e t$ al found elevated risk ratios for cement workers; however, these results were not significant.

The development of COPD requires a long period of exposure to either dust or tobacco or a combination of both, before it becomes 
clinically significant. Most people are diagnosed after the age of 40 and often later in life, hence details about potentitial occupational exposure during the preceding 20-30 years can be hard to recall. ${ }^{9}$

Demolition and cement workers have excessive dust exposure at work because of conditions in their jobs. The demolition worker works at construction sites either to help renovate older buildings or to demolish; both of these procedures are very dust exposed. There are legal requirements when working with, for example, asbestos. However, these regulations might not be met at smaller demolitions. In the cement and concrete production, it is well known that working indoors and processing the cement and concrete, as well as the cleaning procedures, produces a lot of fine dust.

Because of the economic burden of having unhealthy workers and because of the lowering of quality of life when having COPD, ${ }^{9}{ }^{10}$ it is extremely important to clarify the influence of modifiable agents that causes COPD.

The aim of this study was to reveal whether Danish workers in two dusty trades (the demolition and cement industry) have a higher prevalence of hospitalisation by COPD than the entire male labour force.

\section{METHOD}

Data were extracted from the Occupational Hospitalisation Register $(\mathrm{OHR}){ }^{11} \mathrm{OHR}$ is a research database obtained through a record-linkage between three national registers; the central person register, the national patient register and the employment classification module. Currently, the OHR includes every person who has been economically active and an inhabitant of Denmark sometime after 1980.

The national patient register has existed since 1977 and contains data from all hospitals in Denmark (more than $99 \%$ of all admissions). From 1995, it also covers outpatients and emergency ward visits along with the admissions. Diagnoses have been coded according to ICD-10 (international classification of diseases) (WHO-classifications), since 1994.

The Civil Registration System contains information on gender, addresses and dates of birth, death and migration for every person who is or has been an inhabitant of Denmark sometime between 1968 and present time.

Since 1975, a person's occupation and industry have been registered annually in the employment classification module. In 1995 (the baseline of the present study), the industries were coded according to DB93, a national version of NACE (the statistical classification of economic activities in the European Community), ${ }^{11}$ while the occupations were coded according to DISCO-88, which is a national version of the International Standard Classification of Occupations, ISCO-88.

We included both inpatients and outpatients. The focus groups consisted of manual workers (main DISCO-88 group=7, 8 or 9) employed with either manufacturing of cement and concrete products
(DB93=265 100 cement factories; 266110 concrete product factories; 266120 concrete element factories; 266300 manufacture of ready-mixed concrete; 266500 manufacture of fibre cement products or 266600 manufacture of other articles of concrete, plaster and cement), or in the demolition industry (DB93=451 100).

\section{STATISTICS}

All economically active men defined as wage earners, including those on unemployment benefit, selfemployees and independent people, in Denmark, aged 20-59 on 1 January 1995, were classified according to their most important occupation and industry defined as the highest income the previous year. They were followed in the patient register for hospital contacts with a principal discharge diagnosis in the ICD10 interval J40-J47 (chronic lower respiratory disease). Person years at risk (PYRS) were calculated for each individual. A person who did not die, emigrate or become a case during the follow-up contributed with 15 person years (1 January 1995 to 31 December 2009). A person who died, emigrated or became a case during the follow-up period contributed with the amount of years it took from the start of follow-up until the event took place.

With age categorised into 5-year classes and all economically active men as standard population, an age-standardised hospitalisation ratio (SHR) due to COPD was calculated for each of the two occupational categories of interest.

The SHR for an occupational category i, was calculated through the following formula:

$$
\mathrm{SHR}=100 \times \frac{\sum_{\mathrm{j}} \mathrm{OBS}_{\mathrm{ij}}}{\sum_{\mathrm{j}} \frac{\mathrm{OBS}_{\mathrm{j}}}{\mathrm{PYRS}_{\mathrm{j}}} \times \mathrm{PYRS}_{\mathrm{ij}}}
$$

Where $\mathrm{OBS}_{\mathrm{ij}}$ is the observed number of cases and PYRS is the number of person years at risk in occupational category $\mathrm{i}$ and age category $\mathrm{j}$, while $\mathrm{OBS}_{\text {.j }}$ and $\mathrm{PYRS}_{\mathrm{j}}$ are the corresponding numbers in the standard population.

\section{RESULTS}

Table 1 shows that the cement workers have a statistically significant higher SHR for chronic lower respiratory diseases than in the rest of the male labour force after adjusting for age as well as after adjusting for both age and socioeconomic group. The group of demolition workers is rather small, hence the CI is larger, but the tendency is the same among demolition workers as in the cement and concrete workers. It is, therefore, unlikely that smoking explains our results.

Table 2 shows that the cement workers have a statistically higher SHR for chronic lower respiratory disease than the rest of the male labour force. In the group of $45-59$ years of age, it is highly significant. The group of demolition workers is rather small, hence the CI is 
Table 1 'Age'-standardised hospitalisation ratios (SHR) (A) and 'age and social group' SHR (B) due to chronic lower respiratory diseases among male workers in the demolition and cement industry with $95 \% \mathrm{Cl}$

\begin{tabular}{|c|c|c|c|c|c|c|c|}
\hline \multirow[b]{2}{*}{ Job type } & \multirow[b]{2}{*}{ Persons } & \multirow[b]{2}{*}{ Observed } & \multicolumn{3}{|l|}{ A } & \multicolumn{2}{|l|}{ B } \\
\hline & & & Expected & SHR & $95 \% \mathrm{Cl}$ & $\overline{\text { SHR }}$ & $95 \% \mathrm{Cl}$ \\
\hline Demolition worker & 895 & 29 & 22.2 & 131 & 87 to 188 & 112 & 75 to 161 \\
\hline Cement worker & 5633 & 209 & 156.3 & 134 & 117 to 153 & 121 & 105 to 138 \\
\hline
\end{tabular}

larger, but the tendency is the same among demolition workers as in the cement workers, with a higher SHR in the older group.

\section{DISCUSSION}

Our data suggest that the incidence of chronic lower respiratory diseases in cement and demolition workers tend to be higher than in the entire labour force and that the older group (age 45-59) has the highest incidence. We hypothesise that work-related conditions could increase the risk of chronic lower respiratory disease. A cross-sectional study from Norway shows that exposure to dust in cement production may lead to respiratory symptoms and airway obstruction. ${ }^{12}$ In the Netherlands, they showed that even with dust levels below allowed limits $\left(5 \mathrm{mg} / \mathrm{m}^{3}\right)$, there was a reduction in lung function in the workers. ${ }^{6}$ In a review on occupational exposure and development of COPD from USA, they suggest that occupational exposure potentiates the severity of COPD once established. ${ }^{13}$

The prevention of dust exposure is very challenging because of the very unstable and transitional settings at construction sites, where the concrete and demolition workers work. The tasks at the construction site changes from day to day, as do the location of the construction site, which means that protection against dust is difficult. Already legal requirements have been made with regard to removal of dangerous materials. Even though the quantity of dust might have decreased, the nature of dust might also have changed. The particles may become smaller because of new materials, tools and machinery; hence, the dust may be even more harmful in the lower respiratory organs. In the cement industry, the challenges are different; they do not hold the same transitional character at the worksite, but instead, they have the challenge of being indoors and having very dusty procedures in preparing and cleaning cement.

We found that workers above age 45 where in a higher risk of having lower chronic respiratory disease, than their younger colleagues. This is in accordance with the known fact that it takes many years of exposure to a harmful agent before a patient is diagnosed with a chronic lower respiratory disease.

The authors of a former Danish study of cement production worker found risk estimates in line with those of the present study $(\mathrm{RR}=1.1,1.2$, and 0.6 with increasing seniority), but none of the results were statistically significant. ${ }^{8}$ We found relative risk similar to these (1.3, 1.2), but in our study, they were significant; this may be explained by the number of cases included. Our study covers a larger group of cement workers.

The major weakness in the present study is the absence of individual smoking records. We adjusted for social group because unskilled workers are known to smoke more than others. Even after this adjustment, we found that cement and concrete workers had a significantly high SHR owing to chronic lower respiratory disease.

Another weakness is the possibility for misclassification since we only have main job title and the rather unspecific diagnose-codes. We include persons the first time in the follow-up period when they are diagnosed in a hospital setting with J40-J47 which means that they, at this point, probably have had an exacerbation; therefore we might underestimate the number of workers with lower chronic respiratory disease. We lack information on individual exposure (dust and tobacco), and lung function test. However, we consider it as strength that we know the ICD-10 coding instead of having self-reported diagnoses.

It is the strength that we both include inpatients and outpatients because of the nature of chronic lower respiratory diseases, since mild cases of COPD will not

Table 2 Standardised hospitalisation ratios (SHR) due to chronic lower respiratory diseases among male workers in the demolition and cement industry by age group (20-44 and $45-59)$ with $95 \% \mathrm{Cl}$

\begin{tabular}{lllcrrrr}
\hline Job type & Age & Persons & PYRS & Observed & Expected & SHR & 95\% Cl \\
\hline Demolition worker & $20-44$ & 656 & 9410.3 & 16 & 12.8 & 125 & 71 to 203 \\
Demolition worker & $45-59$ & 239 & 3285.7 & 13 & 9.4 & 138 & 74 to 237 \\
Cement worker & $20-44$ & 3547 & 50766.1 & 87 & 70.3 & 124 & 99 to 153 \\
Cement worker & $45-59$ & 2086 & 28408.2 & 122 & 86.0 & 142 & 119 to 169 \\
\hline Denmark 1995-2009. & & & & & &
\end{tabular}


lead to hospitalisation but can be treated in the outpatient clinic. Also, we consider it strength that the OHR covers the entire gainfully employed population of Denmark, so geographic differences are levelled out.

We believe dust to be a potential harmful agent in the development of chronic lower respiratory disease. Also, there is an economic burden of having unhealthy workers and the lowering of quality of life, when having chronic lower respiratory diseases, ${ }^{9}{ }^{10}$ which makes it extremely important to clarify the influence of modifiable agents that causes chronic lower respiratory diseases. Therefore, further studies in the area are needed to better prevent development of chronic lower respiratory diseases due to dust exposure at the workplace.

In conclusion, we find a significant elevated SHR in cement workers and also a comparable use of tobacco in the reference group as in the study group. In the group of demolition workers, there is only a tendency to an elevated SHR; this might be due to the size of the study group.

Contributors EFM prepared the manuscript.. $\mathrm{HH}$ contributed to statistics and analyses. FT contributed to Methods and Discussion. CB and LK contributed to Introduction and Discussion. All the authors reviewed and approved the final draft.

Funding This study was made possible by grant No. 21-2010-09 from the Danish Working Environment Research Fund.

Competing interests None.

Data sharing statement There are no additional data available.

\section{REFERENCES}

1. Aasen T, Blanc P, Brisman J, et al. Occupational COPD. Correlations between chronic obstructive pulmonary disease and various types of physical and chemical exposures at work. Copenhagen: The Danish Working Environment Research Fund, 2009:1-73.

2. Hansen JG, Pedersen L, Overvad K, et al. The Prevalence of chronic obstructive pulmonary disease among Danes aged 45-84 years: population-based study. COPD 2008;5:347-52.

3. Boggia B, Farinaro E, Grieco L, et al. Burden of smoking and occupational exposure on etiology of chronic obstructive pulmonary disease in workers of Southern Italy. J Occup Environ Med 2008;50:366-70.

4. Anonymous. Environmental descriptions of occupations within the construction industry. (Miljöbeskrivning av sysselsättningar inom byggbranschen).Stockholm: Bygghälsan, 1977; Report from Bygghälsan.

5. Bergdahl IA, Torén K, Eriksson K, et al. Increased mortality in COPD among construction workers exposed to inorganic dust. Eur Respir $J$ 2004:402-6.

6. Meijer E, Kromhout $\mathrm{H}$, Heedrik D. Respiratory effects of exposure to low levels of concrete dust containing crystalline silica. Am J Indust Med 2001;40:133-40.

7. Ulvestad B, Bakke B, Meibostad E, et al. Increased risk of obstructive pulmonary disease in tunnel workers. Thorax 2000;55:277-82.

8. Vestbo J, Rasmussen FV. Long-term exposure to cement dust and later hospitalization due to respiratory disease. Int Arch Occup Environ Health 1990;62:217-20.

9. Eisner MD, Anthonisen N, Coultas D, et al. An official American Thoracic Society public policy statement: novel risk factors and the global burden of chronic obstructive pulmonary disease. Am J Respir Crit Care Med 2010;182:693-718.

10. Dibonaventura M, Paulose-Ram R, Su J, et al. The impact of COPD on quality of life, productivity loss, and resource use among the elderly United States workforce. COPD 2012;9:46-57.

11. Tuchsen F, Bach E. Occupation, morbidity, and hospital admission Scand J Public Health 2011;39(7 Suppl):141-6.

12. Nordby KC, Fell AK, Noto H, et al. Exposure to thoracic dust, airway symptoms and lung function in cement production workers1. Eur Respir J 2011;38:1278-86.

13. Blanc PD. Occupation and COPD: a brief review. J Asthma 2012;49:2-4. 